\title{
Limitations on the prognostic value of predischarge data after myocardial infarction
}

\author{
HENRI CLEEMPOEL, HARRY VAINSEL, MICHELE DRAMAIX, * \\ ANDRE LENAERS, EFISIO CONTU, MICHELINE HOYLAERTS, \\ BETTY DEMARET, MICHEL DE MARNEFFE, JEAN-LUC VANDENBOSSCHE, \\ MARC RENARD, RAYMOND HAARDT, MARC ENGLERT, HENRI DENOLIN, \\ ROLAND BERNARD
}

From the Cardiology Department, Saint Peter's University Hospital; and the ${ }^{\star}$ School of Public Health, Free University of Brussels, Brussels, Belgium

SUMMARY Clinical variables and those obtained by non-invasive techniques were studied? prospectively in a series of 306 patients discharged from hospital after an acute myocardial infarction. The predictive value of the data at two and 12 months was assessed by univariate and multivariate analyses. The best correlation was found for age, hypertension, bundle branch block $\frac{0}{\xi_{5}}$ early and late heart failure, $x$ ray cardiothoracic ratio, digoxin use, the number of metabolic? equivalents reached during the stress test, echocardiographic wall motion score index, lef $\mathfrak{1}^{\circ}$ ventricular end diastolic diameter, left ventricular ejection fraction, and the presence of an aneurysm. The prognostic value of the same data at 12 months was studied in those surviving foro two months. There was a noticeable decline in the relative risk of all but two of the factors (numbers of metabolic equivalents, ventricular arrhythmias). All of the predictive variables except the $x$ ray, cardiothoracic ratio, number of metabolic equivalents, and the presence of an aneurysm lost theiro discriminant power. The explanation for this is the strength of statistical relations of these variables with the outcome at two months. They continued to influence the score at 12 months even when the entire patient series was considered.

In conclusion, the study shows that the predictive value of most of the predischarge variables. usually taken into account in the assessment of risk in patients one year after infarction does not extend beyond the first two months.

In a previous prospective study we analysed the clinical data and information obtained by all currently available non-invasive techniques in a series of 202 patients in hospital with acute myocardial infarction. ${ }^{1}$ The relevance and predictive values of some of the resulting indices were then established for a two month follow up period. The study was extended to 306 patients with the aim of assessing the validity of our previous work, extending the survey up to one year, and focusing more attention on follow up of those who survived two months.

Requests for reprints to Dr Henri Cleempoel, Hôpital Universitaire Saint Pierre, Département de Cardiologie, Rue Haute 322, B-1000 Brussels, Belgium.

Accepted for publication 18 April 1988

\section{Patients and methods}

We studied a continuous series of men aged $<70$ whơ were admitted to the coronary care unit from Januar 1981 to March 1985 within 24 hours of the first. clinical signs of myocardial infarction and left tho hospital alive. The criteria for infarction were a peaku serum concentration of creatine kinase $\mathrm{MB}$ that was్ $\geqslant 50 \%$ of the upper normal limit and either the characteristic electrocardiographic signs of myot cardial infarction or a history of prolonged chest paif consistent with this diagnosis. Three hundred an twenty two of the 905 patients admitted with myoz cardial infarction during this selection period mes these criteria. Fifteen patients were excluded becaus $\&$ of severe concurrent illnesses (6) or because the $\Phi$ were foreigners who usually lived abroad (9). Of the remaining 307 patients considered for follow up, one 
died from a non-cardiac illness in the first two months of follow up and another died between the second and twelfth months. So 306 patients were included in the statistical analyses of the two month follow up and 305 were included in the 12 month follow up.

During hospital admission the patients were managed in accordance with the usual clinical indications. Forty five $(15 \%)$ patients were treated with streptokinase. At the time of discharge, 150 (49\%) subjects were taking $\beta$ blockers, $34(11 \%)$ antiarrhythmic drugs, and $25(8 \%)$ digoxin.

All patients were followed up for two and 12 months, with death as the end point. Only one patient was lost to one year follow up. The predictive value of the data collected before discharge was measured at two and 12 months. The predictive value at 12 months was also measured for those who survived the first two months.

\section{VARIABLES}

During the hospital stay 68 variables were investigated as described in our previous report. ${ }^{1}$ They included history; clinical, electrocardiographic, and laboratory data; chest $x$ ray cardiothoracic ratio, and the results of all of the non-invasive tests that were performed-that is treadmill exercise test, $M$ mode and cross sectional echocardiography, gated equilibrium radionuclide ventriculography, and a 24 hour ambulatory electrocardiogram. These tests were carried out between 10 and 12 days after the myocardial infarction, before the date of discharge and without stopping drug treatment.

\section{EXERCISE TEST}

The exercise test was performed on a treadmill. ${ }^{2}$ The maximum exercise level was expressed in metabolic equivalents and heart work was evaluated by the double product (systolic blood pressure $\times$ heart rate). ST changes were considered to be abnormal when there was a displacement of $>1 \mathrm{~mm}$ in three consecutive complexes with a stable baseline. ST depression was measured $0.06 \mathrm{~s}$ after the RST $(\mathrm{J})$ junction.

\section{ECHOCARDIOGRAPHIC ANALYSIS}

Echocardiograms were recorded on an ATL Mk 300. We measured long and short diameters of the left ventricle and the shortening fraction (\%). Segmental wall motion was analysed by standard methods. ${ }^{34}$ The left ventricle wall was divided into 16 segments and each segment was then assigned a number corresponding to the wall motion analysis $(1=$ normal, $2=$ hypokinetic, $3=$ akinetic, $4=$ dyskinetic, $5=$ aneurysm). The sum of these numbers multiplied by 10 and then divided by the number of segments visualised gave the wall motion score index.

\section{GATED EQUILIBRIUM RADIONUCLIDE VENTRICULOGRAPHY}

Gated equilibrium radionuclide ventriculography was performed in the left anterior oblique $\left(40^{\circ}\right)$ and left posterior oblique $\left(30^{\circ}\right)$ projections a few minutes after intravenous injection of $15 \mathrm{mCi}$ of technetium$99 \mathrm{~m}$ labelled human serum albumin. The left ventricular end systolic and end diastolic volumes were measured and the left ventricular ejection fraction was calculated. We used a temporal Fourier transform to evaluate regional wall motion from functional images. 56

\section{TWENTY FOUR HOUR ELECTROCARDIOGRAPHIC} RECORDING

A patient was considered to have ventricular arrhythmias if $\mathbf{2 0 0}$ or more extrasystoles, runs, or ventricular tachycardia ( $\geqslant 5$ beats) were recorded over a 24 hour period. The patients were active and able to walk about in the ward while the electrocardiograms were being recorded.

\section{STATISTICAL ANALYSIS}

The data collected during the hospital stay were analysed for correlations with the occurrence of cardiac death two and 12 months after admission to the coronary care unit. The predictive value of all of the variables was assessed by univariate statistical analysis and stepwise discriminant analysis for both follow up periods. The relative risks for all three periods (two months, 12 months, and from two to 12 months) were also calculated. All the analyses were performed with the Statistical Package for Social Sciences (SPSS), version 8 PO. $^{7-9}$

\section{Results}

Fourteen $(4.6 \%)$ patients died within two months of admission: eight suddenly, one from a recurrent myocardial infarction, and five from heart failure. A further $22(7 \%)$ patients died between two and 12 months: nine from sudden death, six from another myocardial infarction, and seven from heart failure.

UNIVARIATE ANALYSIS

Predictive value at two and 12 months for all patients alive at the time of discharge

Clinical data (table 1).-The mean age difference between those who survived and those who died was significant at the one year follow up only. Hypertension was also predictive of death for the 12 month period only. No significant differences were found for a history of angina, previous infarctions, or 
Table 1 Predictive value (\%) at two and 12 months of clinical, electrocardiographic, and radiological data determined by univariate analysis (for all patients leaving the hospital alive)

\begin{tabular}{|c|c|c|c|c|c|c|}
\hline \multirow[b]{2}{*}{ Variables } & \multicolumn{3}{|l|}{2 months } & \multicolumn{3}{|l|}{12 months } \\
\hline & $\begin{array}{l}\text { Alive } \\
(n=292)\end{array}$ & $\begin{array}{l}\text { Dead } \\
(n=14)\end{array}$ & $p$ & $\begin{array}{l}\text { Alive } \\
(n=269)\end{array}$ & $\begin{array}{l}\text { Dead } \\
(n=36)\end{array}$ & $p$ \\
\hline $\begin{array}{l}\text { Age (mean (SD)) } \\
\text { Hypertension } \\
\text { Angina } \\
\text { Previous MI } \\
\text { Diabetes } \\
\text { Anterior MI } \\
\text { VT, VF } \\
\text { Bundle branch block } \\
\text { Early heart failure } \\
\text { Late heart failure } \\
x \text { ray C:T } \geqslant 50 \\
\text { Digoxin } \\
\beta \text { Blocking agent }\end{array}$ & $\begin{array}{l}56 \cdot 0(8 \cdot 3) \\
26 \\
33 \\
26 \\
25 \\
43 \\
23 \\
8 \\
17 \\
5 \\
39 \\
7 \\
50\end{array}$ & $\begin{array}{l}58 \cdot 8(8 \cdot 3) \\
43 \\
50 \\
50 \\
36 \\
50 \\
36 \\
29 \\
86 \\
21 \\
86 \\
36 \\
36\end{array}$ & $\begin{array}{l}\text { NS } \\
\text { NS } \\
\text { NS } \\
\text { NS } \\
\text { NS } \\
\text { NS } \\
\text { NS } \\
<0.05 \\
<0.001 \\
<0.05 \\
<0.01 \\
<0.001 \\
\text { NS }\end{array}$ & $\begin{array}{l}55 \cdot 8(8 \cdot 4) \\
25 \\
33 \\
26 \\
26 \\
42 \\
24 \\
8 \\
16 \\
4 \\
37 \\
6 \\
50\end{array}$ & $\begin{array}{l}59 \cdot 1(6 \cdot 6) \\
44 \\
36 \\
33 \\
28 \\
52 \\
22 \\
19 \\
53 \\
17 \\
81 \\
22 \\
47\end{array}$ & $\begin{array}{l}<0.05 \text { वे } \\
<0.05 \text { वे } \\
\text { NS } \\
\text { NS } \\
\text { NS } \\
\text { NS } \\
\text { NS } \\
<0.05 \\
<0.001 \\
<0.01 \\
<0.001 \\
<0.01 \\
\text { NS }\end{array}$ \\
\hline
\end{tabular}

diabetes. Neither the infarction site nor the presence of ventricular tachycardia or fibrillation during hospital stay had any significant predictive value. The peak increase in plasma creatine kinase $M B$ was lower in survivors at both two months (mean (SD) 50 (33) $v 91.3(98) \mu \mathrm{g} / \mathrm{ml}$ ) and 12 months (mean $49(91) v$ $71(69) \mu \mathrm{g} / \mathrm{ml})$. Nevertheless, the F test showed a highly significant difference in the variances in both groups. So a $t$ test with "separate variance estimate" was chosen. This showed no significant difference between the mean plasma concentrations of creatine kinase MB. Complete right or left bundle branch block were less frequent at both two and 12 months in those who survived than in those who died. The variables related to deterioration of left ventricle function had especially high predictive values of death. Early heart failure (Killip classes II and III in the first three days after the acute myocardial infarction) was noted in $17 \%$ of the survivors and $86 \%$ of those who had died by two months and 16 and $53 \%$ of the survivors and those who had died by 12 months. Heart failure at the time of discharge (late heart failure) also showed a predictive value at two months
( $5 \%$ v $21 \%$ ) and 12 months $(4 \% v 17 \%)$. A cardiothoracic ratio $\geqslant 50 \%$ and digoxin use were also predictive of death before two and 12 months. Neither $\beta$ blocking agents, nor antiarrhythmic treatment, nor angina at the time of discharge had $\bar{\oplus}$ discriminant value at two and 12 months. Streptokinase did not have any significant impact on prognosis, but only 45 patients received this drug.

Non-invasive procedures-The exercise test (table 2) was undertaken by 295 patients. The one year mortality for this group was $11.5 \%$, compared with $18 \%$ for the patients who were unable to perform the $\overrightarrow{\vec{F}}$ test because of heart related (arrhythmias, heart $\rightrightarrows$ failure) or other reasons. Of the variables that were $\bar{T}$ indicative of exercise capacity, only the mean peako workload, expressed in metabolic equivalents, achieved by the patients was higher in the survivors at two and 12 months. ST depression or elevation? was not of predictive value. Even severe ST depression or elevation ( $>2 \mathrm{~mm}$ ) failed to have predictive value.

Several echocardiographic findings were of interest (table 3 ). The mean value of the wall motion

Table 2 Predictive value at two and 12 months after myocardial infarction of predischarge exercise testing for surviving and $\bar{N}$ dead patients determined by univariate analysis (for all patients leaving the hospital alive)

\begin{tabular}{|c|c|c|c|c|c|c|}
\hline \multirow[b]{2}{*}{ Variables } & \multicolumn{3}{|l|}{2 months } & \multicolumn{3}{|l|}{12 months } \\
\hline & $\begin{array}{l}\text { Alive } \\
(n=282)\end{array}$ & $\begin{array}{l}\text { Dead } \\
(n=13)\end{array}$ & $p$ & $\begin{array}{l}\text { Alive } \\
(n=261)\end{array}$ & $\begin{array}{l}\text { Dead } \\
(n=33)\end{array}$ & $p$ \\
\hline \multirow{2}{*}{$\begin{array}{l}\text { METs (mean (SD)) } \\
\text { Max heart rate (mean (SD)) } \\
\text { Double product (mean (SD)) } \\
\text { ST depression }>1 \mathrm{~mm}(\%) \\
\text { ST elevation }>1 \mathrm{~mm}(\%) \\
\text { Severe ST depression or elevation } \\
\quad(>2 \mathrm{~mm})(\%)\end{array}$} & $\begin{array}{l}3 \cdot 7(1 \cdot 7) \\
102(15) \\
14 \cdot 2(4) \\
42 \\
36\end{array}$ & $\begin{array}{l}2 \cdot 5(1 \cdot 5) \\
105(15) \\
12 \cdot 8(4) \\
25 \\
40\end{array}$ & $\begin{array}{l}<0.01 \\
\text { NS } \\
\text { NS } \\
\text { NS } \\
\text { NS }\end{array}$ & $\begin{array}{l}3 \cdot 8(1 \cdot 6) \\
102(15) \\
14 \cdot 2(4) \\
43 \\
35\end{array}$ & $\begin{array}{l}2 \cdot 4(1 \cdot 5) \\
102(17) \\
13 \cdot 1(4) \\
30 \\
36\end{array}$ & $\begin{array}{l}<0 \cdot 001 \\
\text { NS } \\
\text { NS. } \\
\text { NS } \\
\text { NS }\end{array}$ \\
\hline & 24 & 17 & NS & 23 & 25 & NS \\
\hline \multicolumn{7}{|l|}{ METs, metabolic equivalents. } \\
\hline
\end{tabular}


Table 3 Predictive value at two and 12 months of echocardiographic data for surviving and dead patients determined by univariate analysis (for all patients leaving the hospital alive)

\begin{tabular}{|c|c|c|c|c|c|c|}
\hline \multirow[b]{2}{*}{ Variables } & \multicolumn{3}{|l|}{2 months } & \multicolumn{3}{|l|}{12 months } \\
\hline & $\begin{array}{l}\text { Alive } \\
(n=254)\end{array}$ & $\begin{array}{l}\text { Dead } \\
(n=13)\end{array}$ & $p$ & $\begin{array}{l}\text { Alive } \\
(n=234)\end{array}$ & $\begin{array}{l}\text { Dead } \\
(n=32)\end{array}$ & $p$ \\
\hline $\begin{array}{l}\text { WMSI (mean (SD)) } \\
\text { WMSI > } 22(\%) \\
\text { LVEDD (mean (SD)) } \\
\text { Aneurysm }(\%)\end{array}$ & $\begin{array}{l}15 \cdot 9(5 \cdot 3) \\
13 \cdot 4 \\
57 \cdot 0(6 \cdot 9) \\
12\end{array}$ & $\begin{array}{l}22 \cdot 5(4 \cdot 8) \\
76 \cdot 9 \\
65 \cdot 5(5 \cdot 7) \\
31\end{array}$ & $\begin{array}{l}<0.001 \\
<0.001 \\
<0.001 \\
\text { NS }\end{array}$ & $\begin{array}{l}15 \cdot 8(5 \cdot 3) \\
12 \cdot 8 \\
57 \cdot 0(6 \cdot 9) \\
11\end{array}$ & $\begin{array}{l}19 \cdot 5(5 \cdot 7) \\
43 \cdot 5 \\
60 \cdot 8(8 \cdot 9) \\
28\end{array}$ & $\begin{array}{l}<0.001 \\
<0.001 \\
<0.01 \\
<0.01\end{array}$ \\
\hline
\end{tabular}

WMSI, wall motion score index; LVEDD, left ventricular end diastolic diameter.

score index and scores above 22 had discriminant value at two and 12 months. At two and 12 months the mean left ventricular end diastolic diameter was greater in those who died. Left ventricular aneurysms were statistically less frequent in those who were still alive at 12 months. Radionuclide ventriculography (table 4) showed higher mean left ventricular ejection fractions in survivors at two and 12 months. Left ventricular aneurysms were less frequent in survivors at two and 12 months. Ventricular arrhythmias (as defined above) were less common in the 24 hour electrocardiograms of survivors but the difference was significant at 12 months only.

Predictive values of the same variables at one year for those who survived the first two months (291 cases)

In order to establish their predictive value at 12 months the predischarge data were re-examined for the group that survived the first two months. The non-predictive data for all patients remained nonpredictive for this group.

Table 5 summarises the data with significant prognostic value for all patients (at two or 12 months or both). At 12 months only four of these variables continued to have a significant relation to the outcome in those who survived the first two months. These were a cardiothoracic ratio $\geqslant 50 \%$, the functional capacity during the exercise test, isotopically detected left ventricular aneurysms, and ventricular arrhythmias in the 24 hour electrocardiographic recordings. The other variables lost their predictive, discriminant value.
Table 5 Predictive value (\%) at 12 months of clinical and technical variables determined by univariate analysis (for the patients surviving for the first two months)

\begin{tabular}{|c|c|c|c|}
\hline Variables & Alive & Dead & $p$ \\
\hline 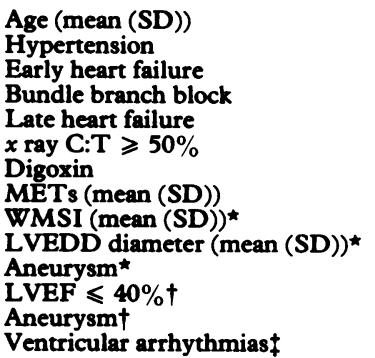 & $\begin{array}{ll}55 & (8 \cdot 4) \\
25 & \\
16 & \\
8 & \\
4 & \\
37 & \\
6 & \\
3 \cdot 8(1 \cdot 6) \\
15 \cdot 8(5 \cdot 3) \\
57 & (6 \cdot 9) \\
11 & \\
24 & \\
17 & \\
26 & \end{array}$ & $\begin{array}{l}59(7 \cdot 2) \\
46 \\
32 \\
14 \\
14 \\
77 \\
14 \\
2 \cdot 3(1 \cdot 5) \\
17 \cdot 4(5 \cdot 6) \\
55 \cdot 5(7 \cdot 8) \\
26 \\
45 \\
55 \\
50\end{array}$ & $\begin{array}{l}\text { NS } \\
\text { NS } \\
\text { NS } \\
\text { NS } \\
\text { NS } \\
<0.001 \\
\text { NS } \\
<0.001 \\
\text { NS } \\
\text { NS } \\
\text { NS } \\
\text { NS } \\
<0.01 \\
<0.05\end{array}$ \\
\hline
\end{tabular}

C:T, cardiothoracic ratio; METs, metabolic equivalents; WMSI, wall motion score index; LVEDD, left ventricular end diastolic diameter.

«Echocardiographic data. †Radionuclide data. $¥ 24$ hour electrocardiogram.

\section{Relative risk of death}

The relative risk of death for a given variable is the ratio of the mortality observed for the group with this factor to the mortality observed for the group without this factor. It was calculated for all variables showing a statistically significant predictive value for at least one of the periods investigated-that is two months, 12 months, and from two to 12 months (table 6).

Comparison of the relative risks of death for the three periods showed large intravariable differences between the periods and intervariable differences for

Table 4 Predictive value at two and 12 months of radionuclide ventriculography for surviving and dead patients determined by univariate analysis (for all patients leaving the hospital alive)

\begin{tabular}{|c|c|c|c|c|c|c|}
\hline \multirow[b]{2}{*}{ Variables } & \multicolumn{3}{|l|}{2 months } & \multicolumn{3}{|l|}{12 months } \\
\hline & $\begin{array}{l}\text { Alive } \\
(n=263)\end{array}$ & $\begin{array}{l}\text { Dead } \\
(n=12)\end{array}$ & $p$ & $\begin{array}{l}\text { Alive } \\
(n=242)\end{array}$ & $\begin{array}{l}\text { Dead } \\
(n=32)\end{array}$ & $p$ \\
\hline $\begin{array}{l}\text { LVEF }(\text { mean }(\text { SD })) \\
\text { LVEF } \leqslant 40(\%) \\
\text { Aneurysm }(\%)\end{array}$ & $\begin{array}{l}48(14) \\
25 \\
19\end{array}$ & $\begin{array}{l}30(13) \\
75 \\
50\end{array}$ & $\begin{array}{l}<0.001 \\
<0.001 \\
<0.05\end{array}$ & $\begin{array}{l}49(13) \\
24 \\
17\end{array}$ & $\begin{array}{l}38(15) \\
56 \\
47\end{array}$ & $\begin{array}{l}<0.001 \\
<0.001 \\
<0.001\end{array}$ \\
\hline
\end{tabular}

LVEF, left ventricular ejection fraction. 
Table 6 Relative risk calculated at two and 12 months (for the entire population and for patients surviving for the first two months)

\begin{tabular}{|c|c|c|c|}
\hline Variables & 2 months & $0-12$ months & 2-12 months \\
\hline $\begin{array}{l}\text { Hypertension } \\
\text { Early heart failure } \\
\text { Bundle branch block } \\
x \text { ray C:T } \geqslant 50 \% \\
\text { Late heart failure } \\
\text { Digoxin } \\
\text { METs }<3 \\
\text { WMSI }>22 \dagger \\
\text { Aneurysm } \dagger \\
\text { LVEF }<40 \% \ddagger \\
\text { Aneurysm } \ddagger \\
\text { Ventricular arrhythmias } \$\end{array}$ & $\begin{array}{c}2 \\
23 \cdot 8^{\star} \\
4^{\star} \\
8 \cdot 5^{\star} \\
4 \cdot 4^{\star} \\
6 \cdot 2^{\star} \\
2 \cdot 4^{\star} \\
17 \cdot 5^{\star} \\
3 \\
7 \cdot 9^{\star} \\
3 \cdot 8 \\
1 \cdot 7\end{array}$ & $\begin{array}{l}2 \cdot 1 \\
4 \cdot 2^{\star} \\
2 \cdot 4^{\star} \\
5 \cdot 7^{\star} \\
3 \cdot 2^{\star} \\
3 \cdot 2^{\star} \\
4 \cdot 0^{\star} \\
3 \cdot 8^{\star} \\
2 \cdot 6^{\star} \\
3 \cdot 3^{\star} \\
3 \cdot 4^{\star} \\
2 \cdot 2^{\star}\end{array}$ & $\begin{array}{l}2 \cdot 3 \\
2 \cdot 2 \\
1 \cdot 8 \\
5 \cdot 1^{\star} \\
2 \cdot 9 \\
3 \cdot 1 \\
6 \cdot 4^{\star} \\
1 \cdot 7 \\
2 \cdot 6 \\
2 \cdot 4 \\
3 \cdot 4^{\star} \\
2 \cdot 6^{\star}\end{array}$ \\
\hline
\end{tabular}

C:T, cardiothoracic ratio; METs, metabolic equivalents; WMSI, wall motion score index; LVEF, left ventricular ejection fraction.

*Predictors of mortality that were statistically significant by univariate analysis. $\nmid$ Echocardiographic data. $¥ R$ adionuclide data. $\$ 24$ h electrocardiogram.

the same period. At two months, the highest risks were associated with early heart failure (23.8) and an $x$ ray cardiothoracic ratio of $\geqslant 50 \%(8.5)$ (for the clinical factors) and a wall motion score index above $22(17.5)$ and an isotopically determined left ventricular ejection fraction $\leqslant 40 \%(17.9)$ (for the nonclinical variables). For all but two factors the relative risk at 12 months for all patients was lower than the relative risk at two months. For metabolic equivalents and arrhythmias the relative risk rose (from 2.4 to 4 and from 1.7 to 2.2 respectively). The decrease in risk was especially pronounced for the two factors that had the highest scores at two months, namely, early heart failure (decreasing from 23.8 to $4 \cdot 2$ ) and a wall motion score index above 22 (falling from $17 \cdot 5$ to $3 \cdot 8$ ). When the risks at 12 months for all of the patients included in the study were compared with those who survived the first two months there was a further decrease in the relative risk for most of the variables. The relative risk remained almost unchanged for the presence of an aneurysm but increased for the metabolic equivalents and ventricular arrhythmias.

Table 7 Independent predictors of death determined by multivariate analysis at two and 12 months follow up (for all patients and for the group surviving the first two months)

\begin{tabular}{llrr}
\hline & \multicolumn{3}{l}{ Standardised coefficient at: } \\
\cline { 2 - 4 } Variables & 2 months & 12 months & $2-12$ months \\
\hline Early heart failure & $0.74^{\star \star \star}$ & $0.35^{\star \star \star}$ & - \\
$x$ ray C:T $\geqslant 50 \%$ & $0.41^{\star \star}$ & $0.57^{\star \star \star}$ & $0.61^{\star \star}$ \\
METs & - & $-0.46^{\star \star \star}$ & $\begin{array}{r}-0.57^{\star \star \star} \\
0.31^{\star}\end{array}$ \\
Aneurysm (radionuclide) & - & - &
\end{tabular}

C:T, cardiothoracic ratio; METs, metabolic equivalents.

${ }^{\star} \mathrm{p}<0.05 ;{ }^{\star \star} \mathrm{p}<0.01 ;{ }^{\star \star \star} \mathrm{p}<0.001$.
MULTIVARIATE ANALYSIS

Stepwise discriminant analysis was performed at two months; it was repeated at $\mathbf{1 2}$ months for the entire: sample group and for those who survived the first two? months.

The following variables were introduced in the discriminant function in the first step: early hearfs failure, $x$ ray cardiothoracic ratio, number of metabolic equivalents reached during the stress test radioisotopically determined left ventricular ejection fraction, bundle branch block, wall motion score? index, and ventricular arrhythmias. Except for hear failure, these variables were weakly correlated $(\max \rho$ imum 0.30).

The following independent predictors of death listed by order of entry, emerged: at two months -i early heart failure (standardised coefficient $0 \cdot 74, p<<_{\infty}$ $0.001)$ and $x$ ray cardiothoracic ratio $\geqslant 50 \%(0.35, \mathrm{po}$ $<0.01)$; at 12 months - early heart failure $(0.35, \mathrm{p}<$ $0.001), x$ ray cardiothoracic ratio $\geqslant 50 \%(0.57, p<>$ 0.001 ), and the number of metabolic equivalents during the stress test $(-0.46, \mathrm{p}<0.001)$. When then 12 month follow up was limited to those whosurvived the first two months, early heart failure disappeared as an independent predictive factor: Two variables remained significant. These were, byo order of entry, $x$ ray cardiothoracic ratio $\geqslant 50 \%$ $(0.61, p<0.01)$ and the number of metabolio equivalents $(-0.57, p<0.001)$, while a ventricula aneurysm detected by the radionuclide method was an independent predictive factor $(0.31, p<0.05) \overrightarrow{0}$ Heart failure, which was highly correlated with the other factors, was excluded in the second step. The same variables remained significant (table 7).

\section{Discussion}

A previous study of 202 patients emphasised the predictive value of simple clinical and non-invasive factors at two months. ${ }^{1}$ The present study, including the first 202 patients and extended to 306 patients and in which all factors retained their earlier sig $\rightarrow$ nificance, confirmed the results of the first study.

The 12 month extended follow up, with only ond patient lost to follow up, showed that the same factors continued to be of prognostic value, especially those that were indicative of impaired left ventriculak $\omega$ function-that is early heart failure, an enlarged heart by radiography, a score $<3$ metabolic equivalents during exercise testing, the echo cardiographically determined wall motion score index, left ventricular ejection fraction, and the presence of an aneurysm (radionuclide method). A history of hypertension became significant. Never $\frac{?}{1}$ theless, the relative risk of death for all but two of the factors was lower at $\mathbf{1 2}$ months than at two months. 
We did not find any relation between ST change and mortality, contrary to other investigators' reports. ${ }^{10-12}$ Surprisingly, ST changes $>1 \mathrm{~mm}$ were more frequent among the survivors. Methodological differences, lower exercise levels (for the patients' safety, testing was stopped if relatively mild subjective and objective signs developed, as confirmed by the low maximum heart rate), and the administration of $\beta$ blockers and digoxin may account, at least partially, for these differences. Nevertheless, the exercise test was carried out between days 10 and 12 in $96 \%$ of our subjects and was thus representative of the entire sample. Furthermore, others have reported the lack of correlation between ST segment changes and survival ${ }^{13-15}$ and bypass surgery performed in some of the patients during the first year of follow up may reduce the predictive value of ST depression..$^{12-15}$ Fifty two of our patients had coronary artery bypass grafts between two and 12 months; the decision to operate was prompted by the results of the exercise test. Of this group, $61 \%$ showed significant ST depression during exercise. The 24 hour electrocardiographic monitoring was done rather early (between days 10 and 12), which may also account for the lack of prognostic value at two months. ${ }^{1}$

When the 12 month follow up was limited to the two month survivors, most of the predictive factors were no longer discriminant (only four out of the 14 were still useful), while the relative risk of death associated with most of the factors declined.

The different statistical methods used (univariate and stepwise discriminant analysis) and relative risk calculations gave similar information. Specifically, the changes in the values of the different factors studied for the three follow up periods followed similar patterns.

The prognostic factors and indices were generally evaluated at 12 months after the acute event. While the results of our 12 month follow up were consistent with current knowledge for most of the variables, the study showed that the one year significance of most of the prognostic factors was influenced by the strength of their ability to predict death at two months. When the very ill patients who died within the two month follow up period were excluded, the findings for the remaining subjects for the two to 12 month follow up period were quite different. This explains why most prognostic variables lost their statistical significance. It is clear that the short term prognosis correlated strongly with the variables related to the size of the infarcted area and the degree of left ventricular dysfunction. After the two month period the long term prognosis is probably most dependent on other factors, such as the course of coronary disease. Further investigations at the end of the second month would probably improve the accuracy of the one year prognosis.
In conclusion, our findings show that the predictive value of most of the predischarge clinical and technical data gathered on acute myocardial patients and used in establishing the 12 month prognosis is only valid in the short term. For two month survivors, more useful information could perhaps be gleaned from data obtained at that time.

\section{References}

1 Cleempoel H, Vainsel H, Bernard R, et al. Predictors of early death after acute myocardial infarction: two months follow-up. Eur Heart $J$ 1986;7:305-11.

2 Markiewicz W, Houston N, DeBusk RF. Exercise testing soon after myocardial infarction. Circulation 1977;56:26-31.

3 Feigenbaum H. Echocardiography. 3rd ed. Philadelphia: Lea and Febiger, 1981:557.

4 Nishimura RA, Reeder GS, Miller FA Jr, et al. Prognostic value of predischarge bidimensional echocardiogram after acute myocardial infarction. Am J Cardiol 1984;51:429-32.

5 Adam WE, Tarkowska A, Bitter F, et al. In: Holman BL, ed. Cardiac nuclear medicine. New York: Springer, 1979:21-3.

6 Bossuyt A, Deconinck P, Lepoudre F, et al. In: Di Paola $\mathrm{R}, \mathrm{Kahn} \mathrm{E}$, eds. Information processing in medical imaging. Paris: Institut Nationale de la Santé et de la Recherche Médicale (Inserm), 1980:vol.88:397-408.

7 Snedecor GW, Cochran WG. Statistical methods. 6th ed. Ames, Iowa: Iowa State University Press, 1957:215-20, 259-98.

8 Morison DF. Multivariate statistical methods. New York: McGraw-Hill, 1967:130-3.

9 Nie NH, Hull CH, Jenkins JG, et al. Statistical package for the social sciences. New York: McGraw-Hill, 1974:424-67.

10 Theroux $\mathrm{P}$, Waters DD, Halphen $\mathrm{CH}$, et al. Prognostic value of exercise testing soon after myocardial infarction. N Engl J Med 1979;301:341-5.

11 Constant J. Prognostic information from early postinfarction exercise testing. $\mathrm{Am} J \mathrm{Med}$ 1986;81: 655-60.

12 Krone RJ, Gillespie JA, Weld FM, et al. Low-level exercise testing after myocardial infarction: usefulness in enhancing clinical risk stratification. Circulation 1985;71:80-9.

13 Sullivan ID, Davies DW, Sowton E. Submaximal exercise testing early after myocardial infarction. Difficulty of predicting coronary anatomy and left ventricular performance. Br Heart J 1985;53:180-5.

14 Fioretti P, Brower RW, Simoons ML, et al. Prediction of mortality in hospital survivors of myocardial infarction. Comparison of predischarge exercise testing and radionuclide ventriculography at rest. $\mathrm{Br}$ Heart $J$ 1984;52:292-8.

15 Fioretti $P$, Brower RW, Simoons ML, et al. The relative value of clinical variables, bicycle ergometry, rest radionuclide ventriculography and 24-hour ambulatory electrocardiographic monitoring at discharge to predict 1-year survival after myocardial infarction. J Am Coll Cardiol 1986;8:40-9. 